\title{
Characterization of Long Descending Premotor Propriospinal Neurons in the Spinal Cord
}

\author{
Yingchun Ni, ${ }^{1 \star}$ Homaira Nawabi, ${ }^{1 \star}$ Xuefeng Liu, ${ }^{1}$ Liu Yang, ${ }^{1}$ Kazunari Miyamichi, ${ }^{2}$ Andrea Tedeschi, ${ }^{1}$ Bengang Xu, ${ }^{1}$ \\ Nicholas R. Wall, ${ }^{3}{ }^{\circledR}$ Edward M. Callaway, ${ }^{3}$ and Zhigang $\mathrm{He}^{1}$ \\ ${ }^{1}$ F.M. Kirby Neurobiology Center, Boston Children's Hospital, Harvard Medical School, Boston, Massachusetts 02115, ${ }^{2}$ Howard Hughes Medical Institute, \\ Department of Biology, Stanford University, Stanford, California 94305, and ${ }^{3}$ Systems Neurobiology Laboratory, The Salk Institute for Biological Studies \\ and Neurosciences Graduate Program, University of California, San Diego, La Jolla, California 92037
}

The motor function of the spinal cord requires the computation of the local neuronal circuits within the same segments as well as the long-range coordination of different spinal levels. Implicated players in this process are the propriospinal neurons (PPNs) that project their axons across different levels of the spinal cord. However, their cellular, molecular, and functional properties remain unknown. Here we use a recombinant rabies virus-based method to label a specific type of long-projecting premotor PPNs in the mouse upper spinal cord that are monosynaptically connected to the motor neurons in the lumbar spinal cord. With a whole spinal cord imaging method, we find that these neurons are distributed along the entire length of the upper spinal cord with more in the lower thoracic levels. Among them, a subset of thoracic PPNs receive substantial numbers of sensory inputs, suggesting a function in coordinating the activity of trunk and hindlimb muscles. Although many PPNs in the cervical and thoracic spinal cord receive the synaptic inputs from corticospinal tract or serotonergic axons, limited bouton numbers suggested that these supraspinal inputs might not be major regulators of the PPNs in intact animals. Molecularly, these PPNs appear to be distinct from other known premotor interneurons, but some are derived from Chx10+ lineages. This study provides an anatomical basis for further exploring different functions of PPNs.

\section{Introduction}

A salient feature of movement in vertebrates is the coordination of different muscle groups at different spinal cord levels. For example, the interplay between hindlimb and trunk, as well as between hindlimb and forelimb muscles, influences many aspects of motor outputs, such as speed, balance, and posture (Grillner, 2006; Garcia-Campmany et al., 2010). However, the anatomical basis of such cross-segmental coordination remains unclear. Although higher brain centers may provide top-down command for intersegmental coordination, long-projection neurons within the spinal cord may be needed to create information highways, allowing the information exchange among the segmental neuronal circuits at different spinal levels. Indeed, Sherrington and Laslett (1902) and (1903) first described a population of spinal cord neurons that connect multiple spinal cord segments and participate in complex motor reflexes. These neurons had their somas and all processes restricted within the

Received May 1, 2014; revised June 1, 2014; accepted June 6, 2014.

Author contributions: Y.N., H.N., and Z.H. designed research; Y.N., H.N., X.L., L.Y., A.T., and B.X. performed research; K.M., N.R.W., and E.M.C. contributed unpublished reagents/analytic tools; Y.N., H.N., X.L., L.Y., A.T., B.X., and Z.H. analyzed data; Y.N., H.N., and Z.H. wrote the paper.

This research was supported by a grant from the International Foundation for Research in Paraplegia (to Z.H.) and Wings for Life (to Y.N.). We thank Drs. Silvia Arber, Liqun Luo, Aya Takeoka, and Ludwig Ruder for help with some data analysis and for critically reading the manuscript.

*Y.N. and H.N. contributed equally to this work.

The authors declare no competing financial interests.

Correspondence should be addressed to Dr. Zhigang He, F. M. Kirby Neurobiology Center, Boston Children's Hospital, Harvard Medical School, Boston, MA 02115. E-mail: zhigang.he@childrens.harvard.edu.

DOI:10.1523/JNEUROSCI.1771-14.2014

Copyright $\odot 2014$ the authors $\quad 0270-6474 / 14 / 349404-14 \$ 15.00 / 0$ spinal cord, and were later named "propriospinal neurons" (PPNs; Chung and Coggeshall, 1983). They were found in different spinal levels, and their axons were of different lengths and innervated motor neurons and interneurons across many spinal segments (Kostyuk and Vasilenko, 1979). Based on their projection patterns, these cross-segmental connections have been speculated to function in the regulation and fine-tuning of locomotion, limb coordination, and postural support, working in concert with supraspinal neurons (Miller et al., 1973; Delwaide et al., 1977; Skinner et al., 1980; Arshavsky Yu et al., 1986; Cowley et al., 2010).

In addition to regulating reflexive functions in intact animals, propriospinal neurons have also been implicated in mediating adaptive changes under pathological conditions such as spontaneous functional recovery after incomplete spinal cord injury (Bareyre et al., 2004; Courtine et al., 2008, 2009; Rosenzweig et al., 2010). For example, after a thoracic lateral injury, a consistent spontaneous locomotion recovery of the hindlimb on the affected side has been documented in many species. A proposed mechanism for such spontaneous recovery is that the propriospinal neurons located in the upper spinal cord with their axons projecting caudally might form relays between the supraspinal descending axons above the lesion and the denervated neurons below the lesion, allowing regained control of denervated motor neurons in the lumbar cord by supraspinal commands (Stelzner, 2008).

Despite the proposed functional significance, little is known about the cellular and molecular properties of these propriospinal neurons. Previous studies on these propriospinal neurons 
have largely relied on conventional dye tracing and electrophysiological recording. Unlike certain descending axonal tracts that form tight bundles, these neurons are distributed and project within the entire spinal cord. Therefore, a major limitation in previous studies is the lack of a reliable and efficient labeling method to identify them in a reproducible manner. In this study, we used a recombinant rabies virus-based method to trace a subset of the long descending propriospinal neurons that form monosynaptic connections directly with motor neurons of the hindlimb tibialis anterior (TA) muscle.

\section{Materials and Methods}

Viral tracing. All experimental procedures were performed in compliance with animal protocols approved by the Institutional Animal Care and Use Committee at Boston Children's Hospital. For all surgical procedures, postnatal day 3 (P3) mice of either sex were anesthetized on ice for $1 \mathrm{~min}$ before muscle injection. Mutant monosynaptic rabies virus $\Delta \mathrm{G}$ GFP was amplified according to a previously published protocol, and the titer is $\sim 10^{9}$ viral particles $/ \mathrm{ml}$ (Wickersham et al., 2007a). A rabies glycoprotein gene was subcloned into the adeno-associated virus (AAV)MCS construct (Stratagene), and serotype 6 of the AAV virus was produced at a titer of $10^{13}$ viral particles/ml, according to a previously published protocol (Grieger et al., 2006; Stepien et al., 2010). An equal mixture of $4 \mu \mathrm{l}$ of rabies virus and AAV was injected into individual mouse muscles through a glass micropipette attached to a $50 \mu \mathrm{l}$ syringe controlled by an UltraMicroPump (World Precision Instruments). The animals were killed $8 \mathrm{~d}$ after viral injection.

Tissue processing. Animals were anesthetized using a ketamine/xylazine mixture and were perfused with cold PBS followed by $4 \%$ paraformaldehyde. After overnight post-fixation, spinal cords were dissected out, and subjected to $15 \%$ and $30 \%$ sucrose dehydration overnight. Tissues were then embedded in optimal cutting temperature medium and cut into $35-\mu \mathrm{m}$-thick frozen sections.

Immunohistochemistry. Tissue sections were incubated with primary antibodies at $4^{\circ} \mathrm{C}$ overnight, followed by labeling with Cy2-, Cy3-, or Cy5-conjugated secondary antibodies (1:200; Jackson ImmunoResearch) at room temperature for $1 \mathrm{~h}$. The following primary antibodies were used: chicken anti-green fluorescent protein (GFP; 1:1000; Abcam); rabbit anti-tdTomato (1:400; Abcam); goat anti-cholinergic acetyltransferase (ChAT; 1:100; Millipore); mouse anti-NeuN (1:50; Millipore); goat anti-calretinin (1:1000; Swant); mouse anti-parvalbumin (PV; 1:1000; Swant); mouse anti-calbindin (1:1000; Swant); guinea pig antivesicular glutamate transporter (VGluT)-1 (1:200; Synaptic Systems); guinea pig anti-VGluT2 (1:200; Synaptic Systems); rabbit anti-vesicular GABA transporter (VGAT; 1:400; Synaptic Systems); rabbit anti-5hydroxytryptamine (5-HT; 1:500; Immunostar); and rabbit anti-Chx10 (1:500; from Dr. Connie Cepko, Harvard Medical School, Boston, MA).

In situ labeling. Rabies glycoprotein G mRNA in situ hybridization was performed as described previously (Nawabi et al., 2010). For fluorescent in situ hybridization, we used Fast Red chromogenic agent (Roche) instead of NBT/BCIP.

In toto experiment. We adapted the in toto staining, as described previously (Moret et al., 2007). Briefly, we dehydrated spinal cords gradually in $25 \%, 50 \%, 75 \%$, and $100 \%$ methanol. Tissues were incubated for $48 \mathrm{~h}$ in primary antibodies and then for $24 \mathrm{~h}$ in secondary antibodies. For clearing, spinal cords were dehydrated again as previously described. Tissues were then cleared using benzyl alcohol/benzyl benzoate $(50 \% / 50 \%)$.

Imaging. 3D imaging of intact spinal cord was performed using Ultraview Vox spinning disk confocal microscope (PerkinElmer) through Volocity 3D image analysis software. The transparent spinal cord was digitally divided horizontally into a number of optical imaging fields of the same size using the software. Neighboring optical fields have $15 \%$ of their areas overlapping to ensure the continuity of images. In each optical field, a series of $Z$-section images is acquired at an interval of $4 \mu \mathrm{m}$ in the dorsal-ventral direction to cover the whole depth of the spinal cord. The images from different optical fields will then be stitched together to create a $3 \mathrm{D}$ view of the whole spinal cord. A $3 \mathrm{D}$ view of the $Z$-projection image of the spinal cord was used to plot the dot map of propriospinal neuronal distribution based on the location of individual neurons along the rostral-caudal direction. Digital transverse sections of the spinal cord were created by reslicing the $3 \mathrm{D}$ images in the $Z$-direction at a thickness of 4 $\mu \mathrm{m}$. All the static images were acquired with a Zeiss LSM700 laser scanning confocal microscope. To plot the dot map of the transverse distribution pattern of propriospinal neurons, the static images of spinal sections are acquired. The central canal of the spinal cord section is designated the $(0,0)$ point in the $x / y$-coordinate system. The $y$-axis is parallel to the dorsal-ventral axle of the spinal cord. Neurons on the ipsilateral or dorsal side of the spinal cord have a positive $x$ or $y$ value. The $x$ and $y$ values of each rabies-infected neuron is its distance to the central canal on the $x$-axis and $y$-axis. The unit of measure used in all of the dot map, and all of the dot maps have the same value range on both the $x$-axis and $y$-axis. Each interneuron is represented by a circle or a square in the $x / y$-coordinate system, resulting in a distribution map of all interneurons. In our bouton analysis, we focused on the number of boutons per cell body. Because the structures of dendrites are much more complicated, which makes it difficult to trace their origins, we only analyzed the synaptic connections to PPN somas to ensure consistency.

\section{Results}

\section{Distribution of the PPNs for the tibialis anterior muscle in the upper spinal cord}

In this study, we focused our analysis on the hindlimb TA muscle, because of its critical role in hindlimb movement and its anatomical accessibility. To uncover the long descending PPNs connected with their motoneurons, we adopted a monosynaptic rabies virus-based trans-synaptic tracing technique (Wickersham et al., 2007b; Stepien et al., 2010; Tripodi et al., 2011). A mixture of monosynaptic rabies virus $\Delta$ G-GFP expressing GFP and AAV serotype 6 encoding the rabies glycoprotein (AAV-G) was coinjected into the TA muscle of wild-type mice at P3 (Fig. 1A). Since the glycoprotein $\mathrm{G}$ carried by AAV-G is required for the replication and propagation of the rabies virus $\Delta \mathrm{G}-\mathrm{GFP}$ (Wickersham et al., 2007b; Stepien et al., 2010; Tripodi et al., 2011), only the motor neurons coinfected by both viruses will enable the rabies virus to transport retrogradely across synapses into their premotor interneurons. Since premotor interneurons do not express the rabies glycoprotein, the rabies virus will stay inside them without further propagation, revealing the premotor circuitry at local spinal cord levels as well as other regions of the spinal cord and the brain.

Pilot studies showed that similar numbers of premotor neurons could be labeled at $8-10 \mathrm{~d}$ after the viral injection. Thus, in this study, the animals were killed for analysis at P11, $8 \mathrm{~d}$ after the viral injection. In these animals, we identified coinfected motor neurons by the coexpression of a motor neuron marker, ChAT, GFP from rabies virus (rabies-GFP), and rabies glycoprotein mRNA (glycoprotein) around the DAPI+ nucleus (Fig. $1 C-G$ ). On average, there are $\sim 11$ motoneurons $(\mathrm{GFP}+/$ rabies-glycoprotein + ) infected per animal. An example of the lumbar premotor circuitry shows the infected motor neurons in the ventral horn (Fig. $1 B$ ) and their local premotor interneurons on both the ipsilateral and contralateral sides of the spinal cord, which is consistent with previous reports (Stepien et al., 2010; Tripodi et al., 2011). In these animals, rabies virusinfected GFP-expressing neurons were found in the upper spinal cord, at both the thoracic (Fig. $1 H$ ) and cervical levels (Fig. 1I), fitting with the criteria of long descending PPNs.

Because of the widespread distribution of PPNs, it will not be feasible to analyze their distributions and morphologies with conventional histological methods. Thus, we used a clarification protocol to make the intact spinal cords transparent, which allows us to image the rabies GFP fluorescence of PPNs in intact spinal cords with a confocal microscope (Fig. 2A). Serial confocal 
A

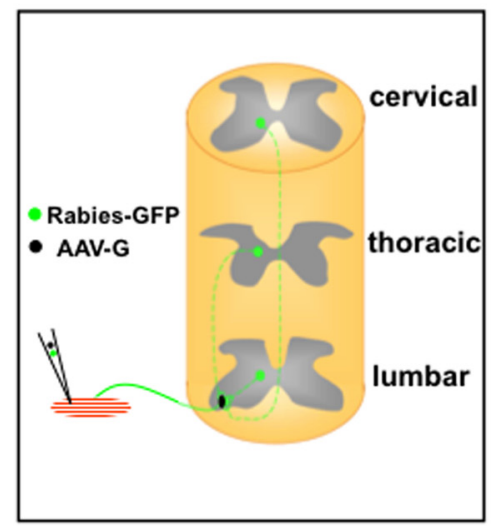

B

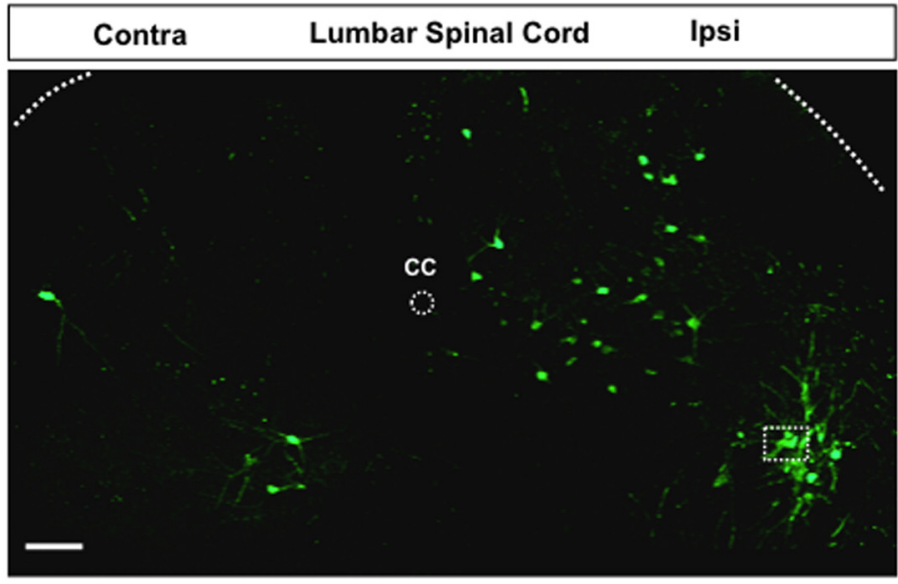

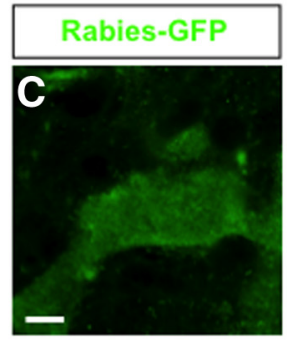
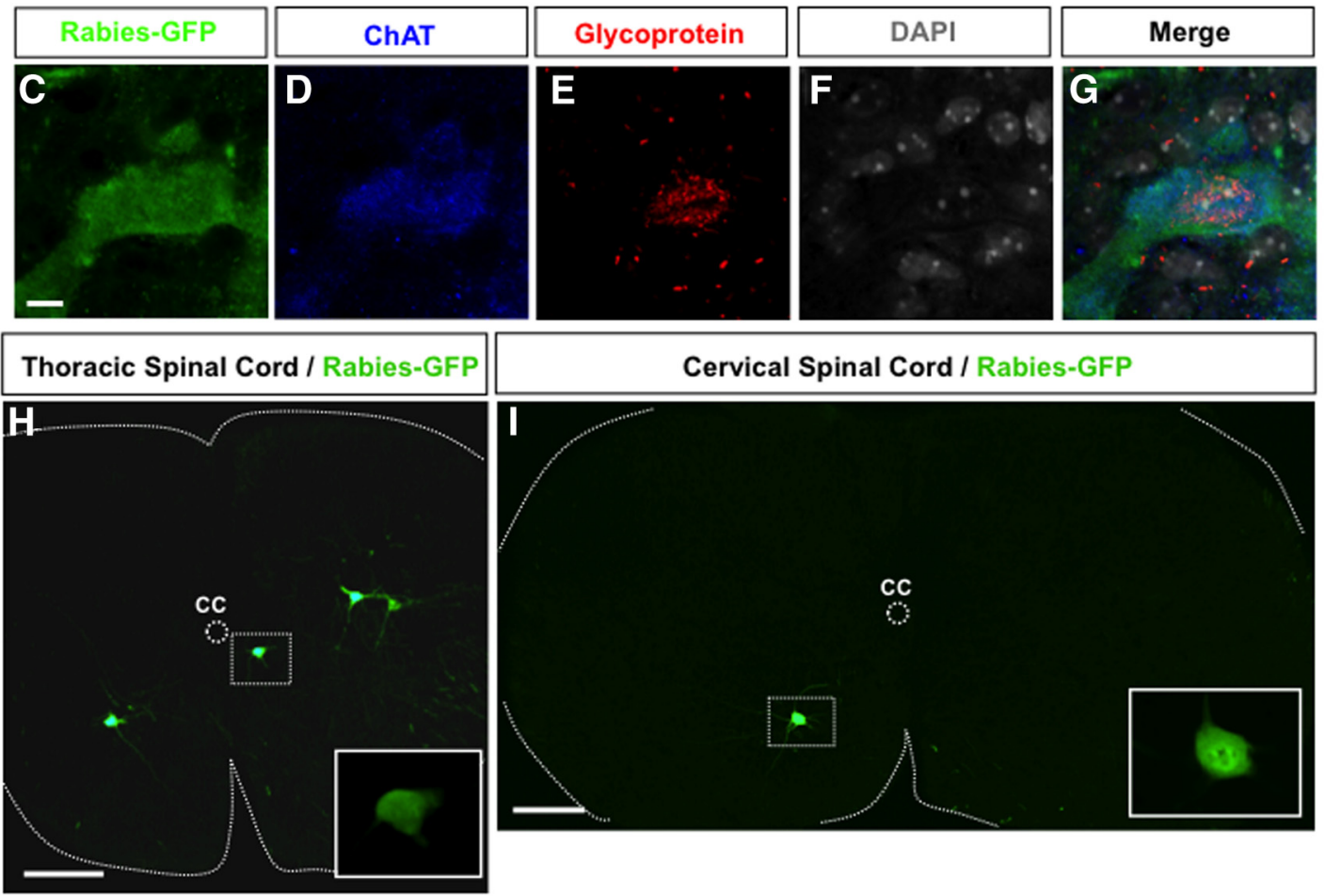

Figure 1. Trans-synaptic labeling of long descending premotor PPNs at the cervical and thoracic spinal levels. $\boldsymbol{A}$, A schematic diagram of the experimental paradigm. A mixture of Rabies-GFP and AAV-G is injected into the hindlimb muscle TA of a P3 wild-type mouse. Coinfected motor neurons will produce rabies viral particles to be transported across synapses to their premotor interneurons in the lumbar spinal cord and PPNs in the upper spinal cord. $\boldsymbol{B}$, An image of a transverse lumbar spinal section after injection of TA muscle with rabies virus and AAV-G shows infected motor neurons and local premotor interneurons. A coinfected motor neuron is highlighted in the boxed area. $\mathbf{C}-\mathbf{G}$, High-magnification images show the marked motor neuron in B-expressing rabies protein (rabies-GFP), ChAT, and rabies glycoprotein mRNA. The section is counterstained with nuclei marker DAPI. $\boldsymbol{H}, \boldsymbol{I}$, Transverse sections from thoracic $(\boldsymbol{H})$ and cervical $(\boldsymbol{I})$ levels show rabies-GFP expressing long descending PPNs. The inset images in $\boldsymbol{H}$ and $\boldsymbol{I}$ are close-up views of the PPNs marked in the boxed area. CC, Central canal; Ipsi, ipsilateral side; Contra, contralateral side. Scale bars: $\boldsymbol{B}, 100 \mu \mathrm{m} ; \boldsymbol{C}-\boldsymbol{G}, 10 \mu \mathrm{m} ; \boldsymbol{H}, \boldsymbol{I}, 200 \mu \mathrm{m}$.

laser-scanning images were obtained throughout the entire spinal cord and were stitched together using software to generate digital maps of individual PPNs in the spinal cords (Fig. 2B). It appears that as the spinal level changes from T13 to C1, the density of PPNs gradually decreases on both sides of the spinal cord (Fig. 2B). As illustrated in the longitudinal dot map shown in Figure $2 E$, the majority of the labeled PPNs were seen in the lower thoracic levels, and fewer numbers were seen in the upper thoracic and cervical levels, which is further supported by quantification analysis (Fig. $2 J$ ). On average, there are $\sim 163$ thoracic and 5 cervical PPNs labeled per animal. Examination at later time points after the viral injection yielded similar results (data not shown), suggesting that a rostrocaudal difference is not entirely due to the distances between the lumbar motor neurons and the somas of their PPNs. Similar to premotor interneurons in lumbar levels (Stepien et al., 2010), significantly fewer PPNs were labeled on the contralateral side, compared with those on the ipsilateral side of the spinal cord (Fig. 2I). Although previous studies on the hindlimb motor controls have been focused on the neurons in the lumbar enlargements (Stepien et al., 2010; Tripodi et al., 2011), our results demonstrated that abundant premotor neurons exist in the upper spinal cord, particularly at the lower thoracic levels, which points to a role for these PPNs in controlling the activity of the hindlimb motor neurons.

In addition to the distribution, close-up examination revealed the morphology of individual PPNs, and two examples on the 
A
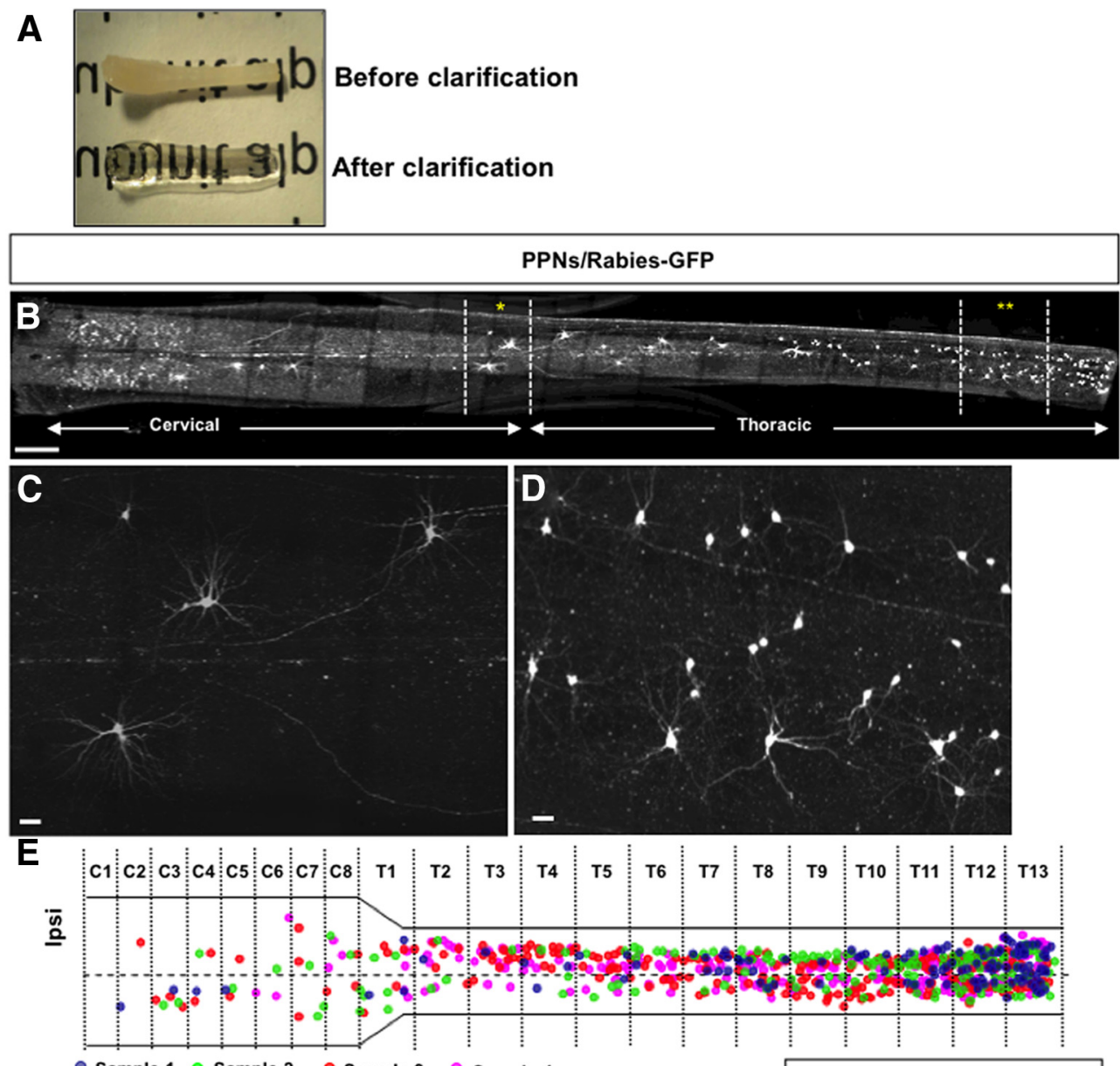

- Sample-1 Sample-2 $\odot$ Sample-3 $\odot$ Sample-4
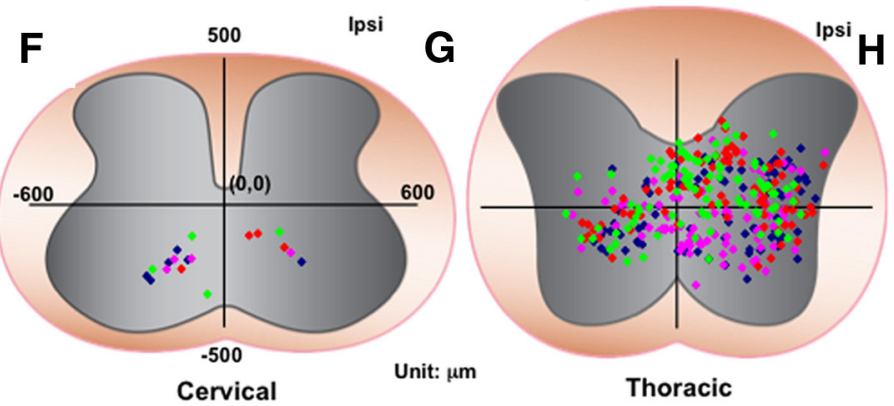

H

Correlation Analysis of PPNs Distribution
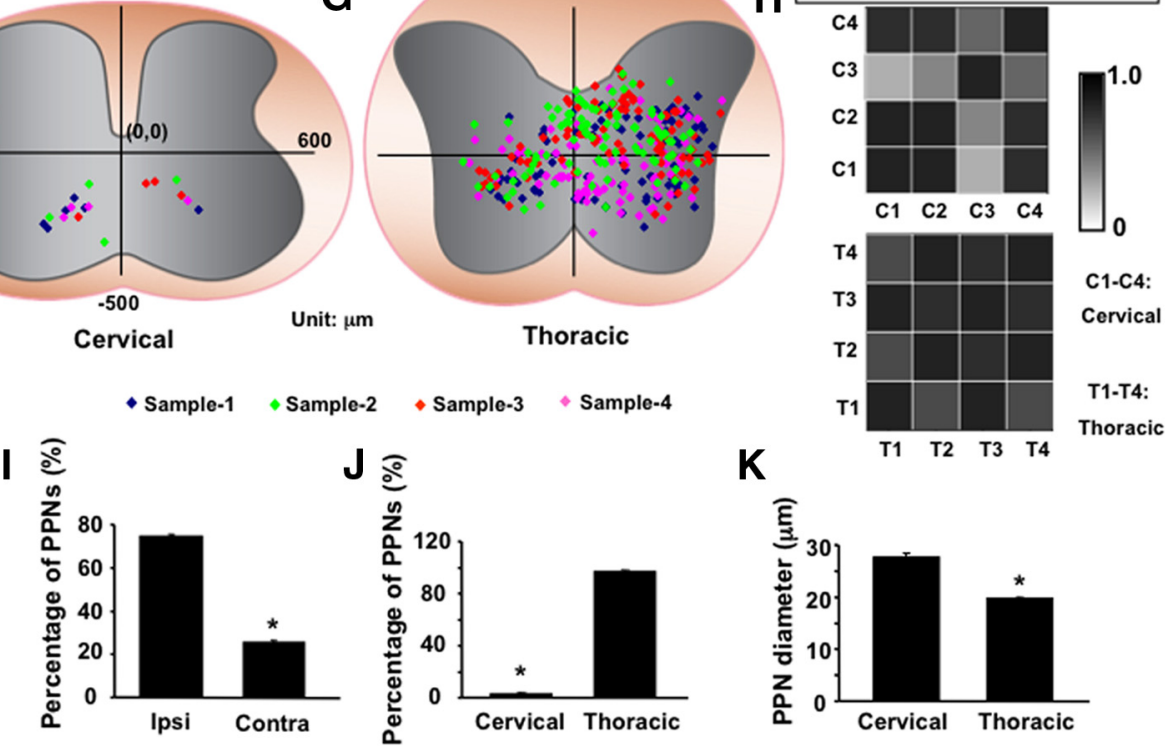

K

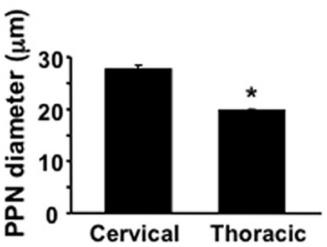

Figure 2. Distribution and morphology of the PPNs in the upper spinal cord for TA muscle. $\boldsymbol{A}$, A photograph shows a spinal cord before (top) and after (bottom) clarification treatment. $\boldsymbol{B}$, A projection image of stitched stacks of confocal images of intact spinal cord C1-T13 stained with GFP antibody shows the distribution of PPNs. Two areas in the spinal cord are highlighted by asterisks. $\boldsymbol{C}, \boldsymbol{D}$, High-magnification images of the two areas indicated by asterisks in $\boldsymbol{B}$. $\boldsymbol{E}$, A dot map illustrates the longitudinal distribution of PPNs. Each PPN from an individual sample is represented by a single colored dot. The middle line of the spinal cord is marked by a horizontal dotted line in the spinal cord diagram. Ipsi, Ipsilateral side. $F, G$, Dot maps show transverse distribution patterns of cervical $(\boldsymbol{F})$ and thoracic $(\boldsymbol{G})$ PPNs. Each color represents one sample. $\boldsymbol{H}$, Correlation analysis of the four samples with Pearson's coefficient shows the degree of consistency in the distribution patterns among the four samples: 0 represents zero degree of correlation, and 1 represents full degree of correlation. T1-T4 represent the four distribution patterns at the thoracic level, and $(1-C 4$ represents the four distribution patterns at the cervical level. I, Bar graphs show the percentage of PPNs on ipsilateral (Ipsi) and contralateral (Contra) sides of the spinal cord (Ipsi, $75 \pm 1 \%$; Contra, $25 \pm 1 \%$; $n=3$ ). J, Bar graphs show the percentage of PPNs at the cervical and thoracic spinal levels (cervical, $3 \pm 0.8 \%$; thoracic $=97 \pm 0.8 \% ; n=3$ ). $\boldsymbol{K}$, Bar graphs compare the average diameters of PPN cell bodies at the cervical and thoracic levels (cervical, $28 \pm 0.75 \mu \mathrm{m}, n=36$; thoracic, $20 \pm 0.17 \mu \mathrm{m}, n=337$ ). Scale bars: $\boldsymbol{B}, 500 \mu \mathrm{m} ; \boldsymbol{C}, \boldsymbol{D}, 30 \mu \mathrm{m}$. ${ }^{*} p<0.05$, Student's $t$ test. 
thoracic and cervical levels are shown in Figure 2, $C$ and $D$. While most PPNs on the cervical level have large somas and elaborated processes (Fig. 2C), the ones on the thoracic level are more heterogeneous in their size and morphology (Fig. 2D). Quantification suggested that the average diameters of the PPN somas on cervical levels are significantly larger than those on thoracic levels (Fig. $2 K$ ).

The image stack also allowed us to visualize the distribution of the PPNs at dorsoventral orientations. As illustrated in the dot maps from representative animals, the distribution patterns of the PPNs are different between the cervical (Fig. $2 F$ ) and thoracic (Fig. 2G) levels. On the cervical levels (Fig. 2F), all labeled PPNs were seen in lamina VII and VIII, on both the ipsilateral and contralateral sides. As these regions are known to be critical in motor control (Heise and Kayalioglu, 2009), our results suggested that these cervical PPNs might play a role in interlimb motor coordination. However, most of the thoracic PPNs were detected in the entire intermediate laminae of the spinal cord, distributed from lamina IV to VIII (Fig. 2G), suggesting that these thoracic PPNs may integrate both motor and sensory inputs along the trunk region and then regulate the activity of motor neurons in the lumbar spinal cord.

To assess the consistency of the PPN distribution in transverse spinal sections, correlation analysis from four animals indicates that the distribution pattern of thoracic spinal PPNs shows a high degree of consistency among the four samples, while at the cervical level three of four samples show a high degree of consistency (Fig. 2H, Pearson's coefficient), possibly due to a lower number of neurons. Nevertheless, this analysis suggested that our distribution results are unlikely to result from the animal variations.

A group of spinal interneurons that connect with sensory fibers were discovered recently using a similar labeling method (Zampieri et al., 2014). These neurons appear to be part of the local sensory-motor reflex circuits and are located in the local spinal cord. However, in this study we are focusing our analysis on the labeled neurons in the upper spinal cord levels, therefore making it unlikely that they result from the connections with sensory afferents.

\section{A subset of thoracic PPNs receive direct sensory inputs}

As a first approach to explore their functions, we examined the presynaptic inputs to these labeled PPNs after viral injection to the TA muscle. Sensory afferents are an integral part of the spinal motor circuit, providing feedback information about the position of muscles and organs. Within the same spinal segments, Ia and $\mathrm{Ib}$ inhibitory interneurons receive proprioceptive inputs from muscle spindles and the Golgi tendon organ, and provide direct feedback to spinal motor neurons, thus tuning the activity of extensor and flexor muscles. It is recognized that the trunk positions influence the movement of hindlimb muscles during locomotion (Grillner and Wallén, 2002; Falgairolle et al., 2006). However, the neuronal pathways to relay proprioceptive inputs from trunk muscles to the motor neurons in the lumbar cord have not been characterized.

To test whether these PPNs are directly innervated by sensory inputs, PV and VGluT1 antibodies were used to label sensory boutons in the spinal cord (Fig. $3 A, C$ ). As expected, most of proprioceptive sensory fibers terminate at the dorsomedial part of the spinal cord (Fig. $3 A-C$ ). We found that some thoracic PPNs are located in sensory afferent termination zone and also receive a large number of synaptic inputs from sensory fibers (Fig. 3C). The average number of sensory boutons that each PPN receives is $\sim 7 \pm 0.6$ per PPN (see Fig. $6 A$ ), suggesting that for this subset of PPNs significant portion of presynaptic inputs are from sensory axons. In contrast, we fail to detect direct sensory synaptic inputs on those thoracic PPNs located outside of the sensory axon termination zone, and on all cervical PPNs (Fig. 3C,D).

To further confirm that these thoracic PPNs relay proprioceptive sensory inputs from the thoracic region to lumbar motoneurons, we injected rabies-GFP into hindlimb muscles, which efficiently infected proprioceptive sensory neurons and stained the spinal sections with antibodies against GFP and parvalbumin (Fig. 3E-J). At the lumbar level, a large number of GFP-labeled cutaneous and GFP+/parvalbumin + proprioceptive neurons can be seen projecting into the dorsal spinal cord and near the central canal (Fig. $3 H-J$ ), whereas at the thoracic level no GFP+/ parvalbumin + fibers were detected (Fig. $3 E-G$ ). Thus, the sensory boutons observed on thoracic PPNs are likely from the local trunk region. Thus, our results identified a subset of PPNs in the thoracic spinal cord with direct innervations from trunk muscles and direct outputs to lumbar motor neurons, which might participate in mediating the coordination of trunk and hindlimb movement.

\section{Supraspinal inputs into TA-specific PPNs}

As mentioned above, a proposed function of the long descending propriospinal neurons in the upper spinal cord is to form intraspinal relay pathways, mediating spontaneous functional recovery after incomplete spinal cord injury (Bareyre et al., 2004; Courtine et al., 2008; Siebert et al., 2010). Because of the existence of other types of propriospinal neurons, it is unknown whether the premotor PPNs could act as relays. We thus test whether the PPNs for TA motoneurons receive synaptic inputs from supraspinal descending axons in intact animals. Although multiple descending tracts might be relevant, our studies focused on cortex-derived corticospinal tract (CST) and brainstem-derived serotonergic (i.e., 5-HT) axons, because of the available genetic methods to efficiently label these tracts (Lee et al., 2010; Tuszynski and Steward, 2012).

To label CST axons, we crossed a floxed tdTomato reporter line with a forebrain-specific Emx-Cre, resulting in a mouse line (Emx-Cre $\times$ Rosa-STOP-tdTomato), which expresses tdTomato in CST axons specifically within the spinal cord (Fig. 4A, B; Bareyre et al., 2005). In these animals, the PPNs were labeled with coinjection of GFP-rabies virus and AAV-G into the TA muscle. Spinal cord sections containing rabies-infected PPNs were immunostained with antibodies against GFP (a rabies viral marker), tdTomato (a CST axon marker), and VGluT1 (a presynaptic marker; Varoqui et al., 2002; Bareyre et al., 2005; Persson et al., 2006; Maier et al., 2008). The structures costained with VGluT1 and tdTomato in apposition to the GFP+ somas and proximal dendrites of the PPNs were considered to be CST boutons. Examples of rabies-infected thoracic (Fig. 4C) and cervical (Fig. 4E) PPNs contacted by a tdTomato + and VGluT1 + CST terminal are shown. Quantification indicated that, despite region differences, dot maps indicate that many (38\%) PPNs receive synaptic inputs from CST fibers on both thoracic levels (Fig. 4C,D) and cervical levels (Fig. 4E, F).

We also used an antibody against 5-HT to detect serotonergic axons and their synaptic sites in the spinal cord sections (Fig. $5 A, B)$. It appears that a majority $(57 \%)$ of PPNs are contacted by 5 -HT boutons on both sides of the spinal cord at the thoracic (Fig. 5C,D) and cervical (Fig. 5E, F) levels. Further examination indicated that in the thoracic levels CST axons preferentially innervate PPNs in the dorsal spinal cord, but 5-HT fiber-contacted PPNs distribute in all parts of the spinal cord (Fig. 6B-D). How- 

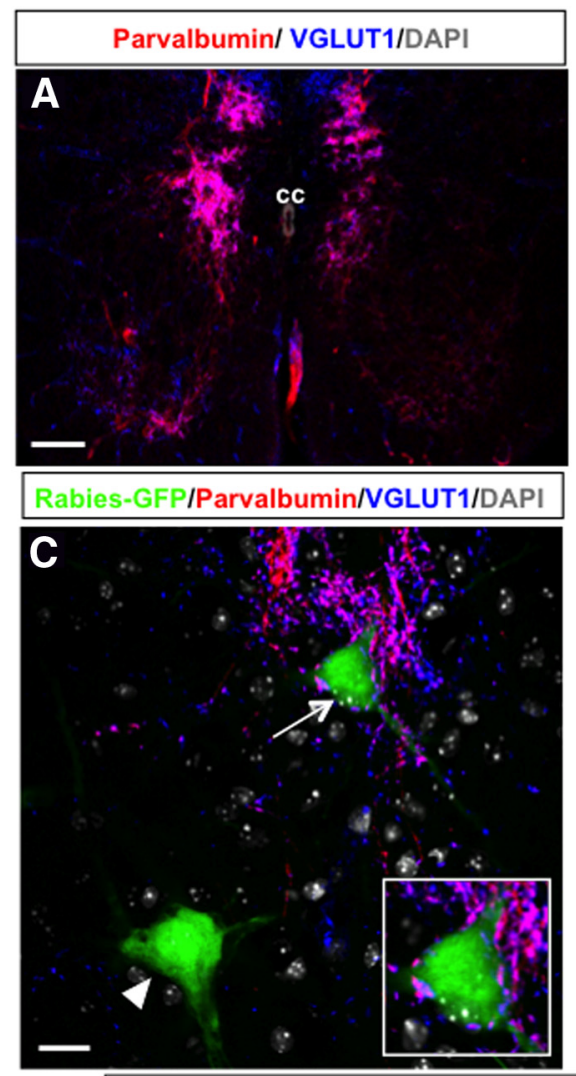

Rabies-GFP/Parvalbumin/DAPI
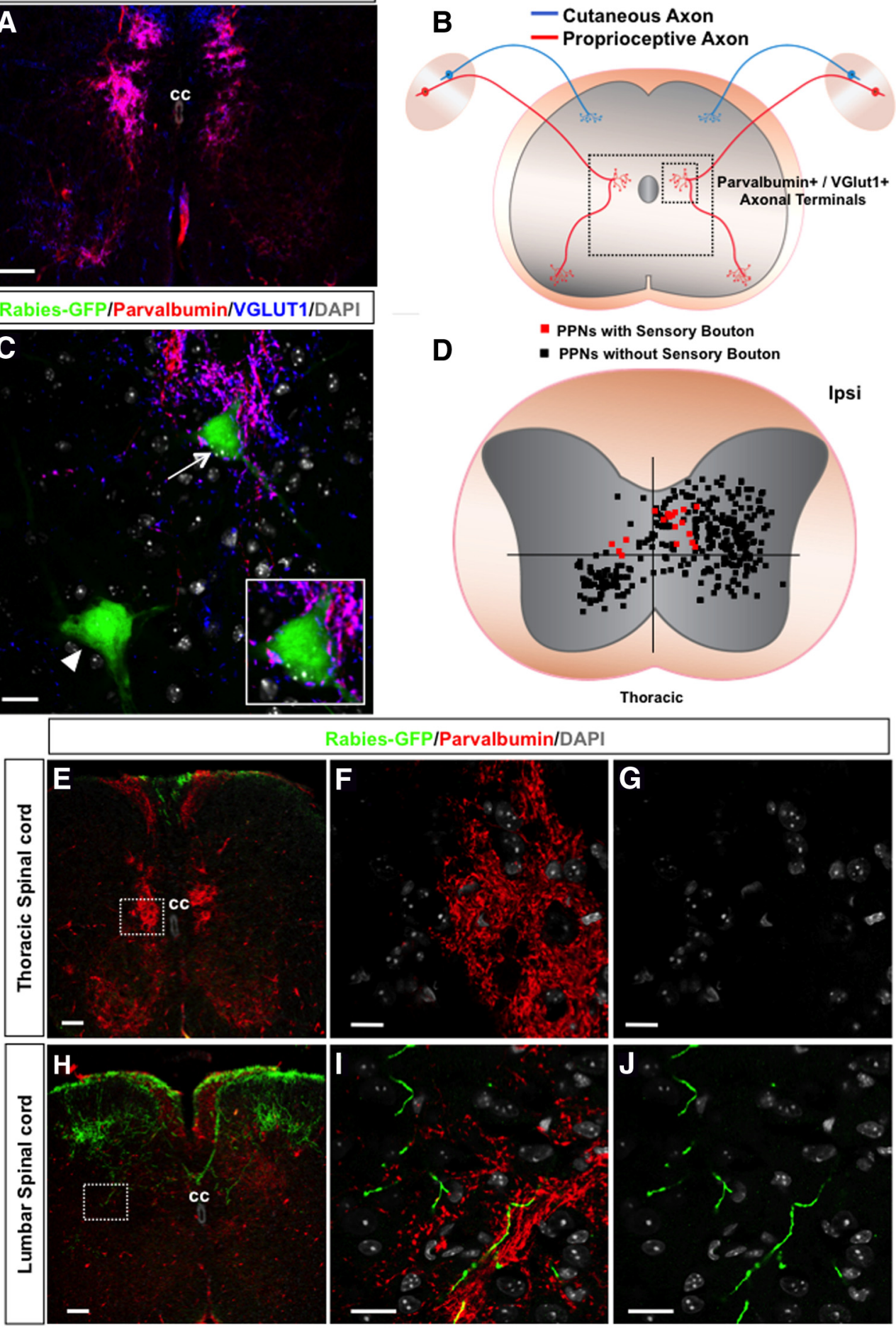

Thoracic

Figure 3. Sensory synaptic inputs to PPNs. A, An image of a wild-type mouse spinal section immunostained with antibodies against parvalbumin and VGluT1 labeling sensory fibers and their axonal terminals. The section is counterstained with nuclei marker DAPI. B, A diagram of sensory axons and their terminals in the spinal cord. The large and small boxed areas mark the location of the regions shown in $\boldsymbol{A}$ and $\boldsymbol{C}$, respectively. $\boldsymbol{C}$, Immunostaining of a thoracic spinal section with antibodies against GFP (rabies-GFP), parvalbumin, and VGluT1 together with DAPI labeling. Sensory axonal terminals (purple) are colabeled with both parvalbumin and VGluT1. The PPN marked with an arrowhead does not have any synaptic connection with sensory fibers, while the other PPN marked with an arrow is contacted by several sensory boutons, which is further highlighted in the inset. $\boldsymbol{D}$, The dot map represents the distribution pattern of thoracic PPNs contacted (red squares) and not contacted (black squares) by sensory axons. Each square represents one neuronal cell body. $\boldsymbol{E}-\boldsymbol{G}$, Distribution of sensory axonal projections originating from the lumbar level in the thoracic spinal cord. $\boldsymbol{E}$, A thoracic spinal section immunostained with antibodies against GFP and parvalbumin to colabel lumbar sensory axons. The section is counterstained with DAPI. $\boldsymbol{F}$, High-magnification image of the boxed area in $\boldsymbol{E}$ with GFP, parvalbumin, and DAPI staining shows no GFP-positive sensory axons. $\boldsymbol{G}$, High-magnification image of the same area in $\boldsymbol{F}$ with only GFP and DAPI channels further identifies the lack of GFP-positive sensory projections. $\boldsymbol{H}-\boldsymbol{J}$, Distribution of sensory axonal projections originating from the lumbar level in the lumbar spinal cord. $\boldsymbol{H}$, A lumbar spinal section shows sensory axonal projections. $\boldsymbol{I}$, High-magnification image of the boxed area in $\boldsymbol{H}$ with GFP, parvalbumin, and DAPI staining shows GFP-positive and parvalbumin-positive sensory axons. $\boldsymbol{J}$, High-magnification image of the same area in I with only GFP and DAPI channels further identifies the GFP-positive sensory projections in the area. CC, Central canal; Ipsi, ipsilateral side. Scale bars: A, $100 \mu \mathrm{m} ; \boldsymbol{C}, 20 \mu \mathrm{m} ; \boldsymbol{E}, 100 \mu \mathrm{m} ; \boldsymbol{F}, \mathbf{G}, \mathbf{I}, \mathbf{J}, 10 \mu \mathrm{m}$ 

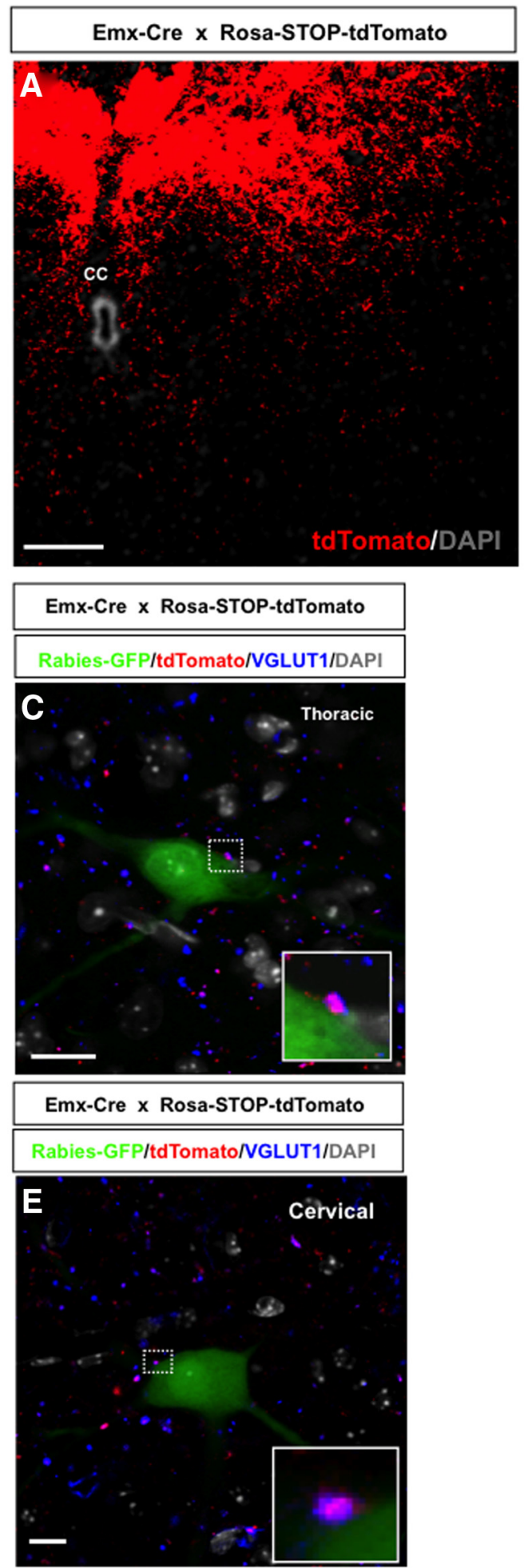

B
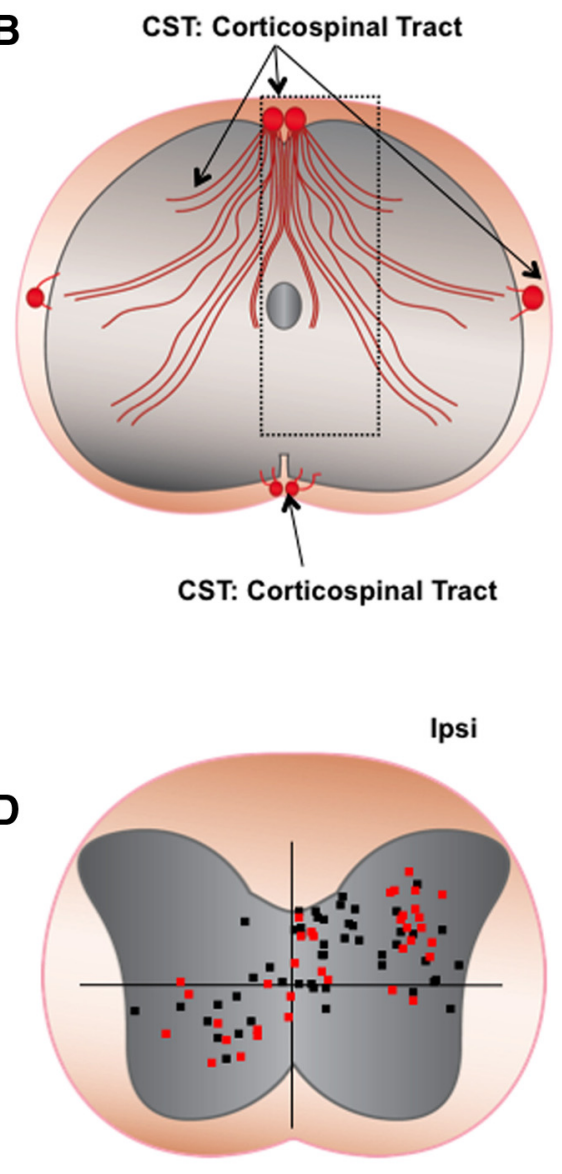

Thoracic

- PPNs with CST Bouton

- PPNs without CST Bouton

Ipsi

$\mathbf{F}$

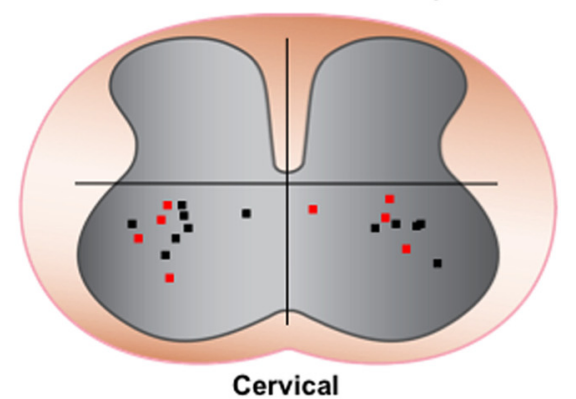

Figure 4. CST presynaptic inputs to PPNs. A, A thoracic transverse section from an Emx-Cre $\times$ Rosa-STOP-tdTomato mouse immunostained with an antibody against tdTomato shows the CST main bundles and axonal ramifications. The section is counterstained with DAPI. $\boldsymbol{B}$, A diagram of CST axonal bundles and axonal ramifications in the spinal cord. The boxed area represents the location of the region shown in $A$. C, Immunostaining of a thoracic spinal section from Emx-Cre $\times$ Rosa-STOP-tdTomato mouse with antibodies against GFP (rabies-GFP), tdTomato, and VGluT1 together with DAPI labeling. CST axonal terminals (purple) are colabeled with both tdTomato and VGluT1. The boxed area in the image highlights the CST synaptic contact with the PPN. The inset is a close-up view of the synaptic contact. $\boldsymbol{D}$, A dot map represents the distribution of thoracic PPNs contacted (red squares) and not contacted (black squares) by (ST axons. $\boldsymbol{E}, \mathrm{A}$ cervical section from an Emx-Cre $X$ Rosa-STOP-tdTomato mouse immunostained with antibodies against GFP (rabies-GFP), tdTomato, and VGluT1 shows a rabies-infected cervical PPN contacted by a CST bouton (tdTomato + and VGluT1+). The section is counterstained with DAPI. A high-magnification image of the bouton is shown in the inset. $F$, The distribution of cervical PPNs with (red squares) or without (black squares) CST boutons in the cervical spinal cord. CC, Central canal; Ipsi, ipsilateral side. Scale bars: $A, 50 \mu \mathrm{m} ; C, 20 \mu \mathrm{m} ; E, 15 \mu \mathrm{m}$. 


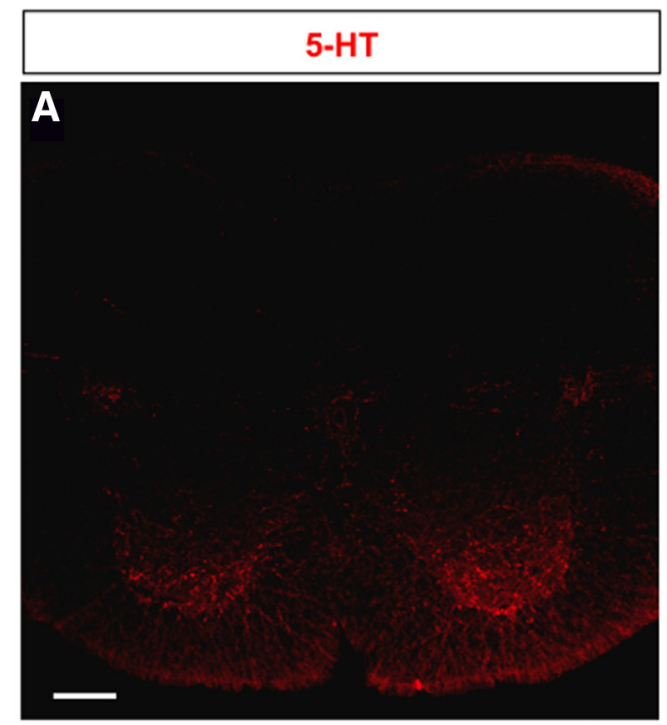

Rabies-GFP/5-HT/NeuN/DAPI

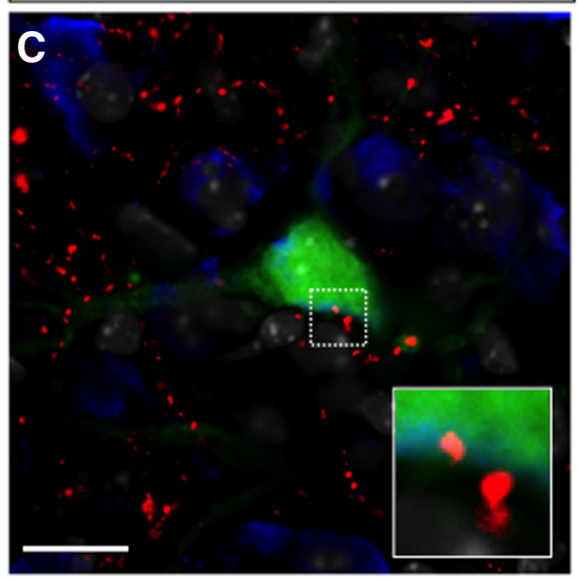

Rabies-GFP/5-HT/NeuN/DAPI

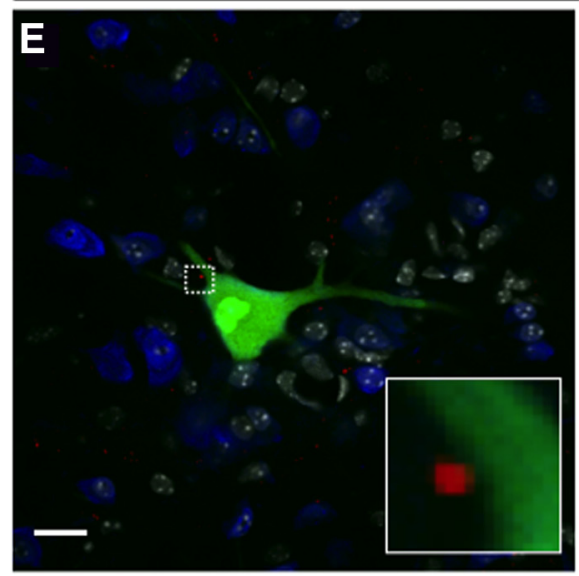

B

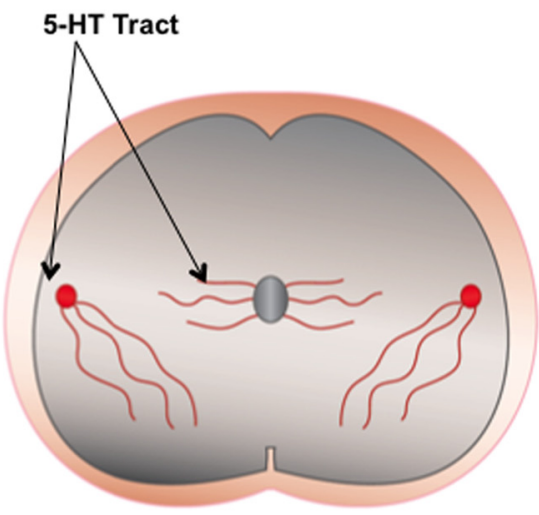

D

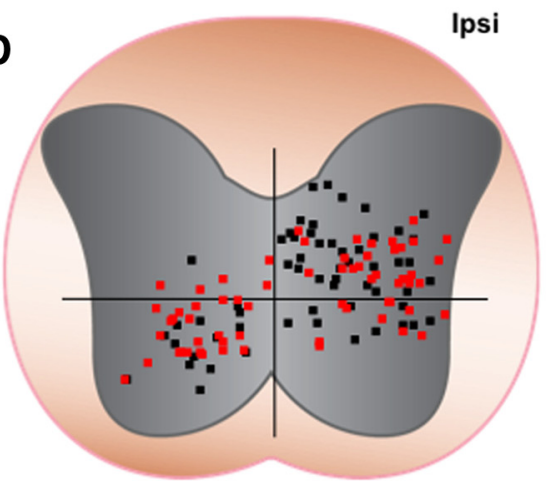

Thoracic

- PPNs with 5-HT Bouton

a PPNs without 5-HT Bouton

$\mathbf{F}$

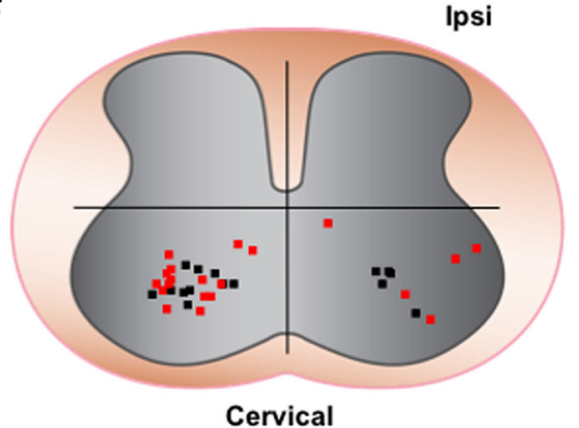

Figure 5. 5-HT presynaptic inputs to PPNs. A, An immunostaining image of wild-type mouse spinal cord section with 5-HT antibody. B, A diagram of 5-HT axons in the spinal cord. C, Immunostaining of a thoracic spinal section of a wild-type mouse with antibodies against GFP (rabies-GFP), 5-HT, and NeuN together with DAPI labeling. The boxed area highlights the 5-HT contact with the PPN, and the inset is the close-up view of the bouton. D, A dot map represents the distribution patterns of thoracic PPNs contacted (red square) and not contacted (black square) by 5-HT axons. $\boldsymbol{E}$, An image of a wild-type mouse cervical spinal section immunostained with antibodies against GFP (rabies-GFP) and 5-HT showing a rabies-infected cervical PPN contacted by two 5 -HT boutons. A high-magnification image of the boutons is shown in the inset. The spinal section is counterstained with NeuN and DAPI. $\boldsymbol{F}$, The distribution of cervical PPNs with (red squares) or without (black squares) 5-HT boutons in the cervical spinal cord. Scale bars: $A, 100 \mu \mathrm{m} ; C, 20 \mu \mathrm{m} ; \boldsymbol{E}, 15 \mu \mathrm{m}$. 

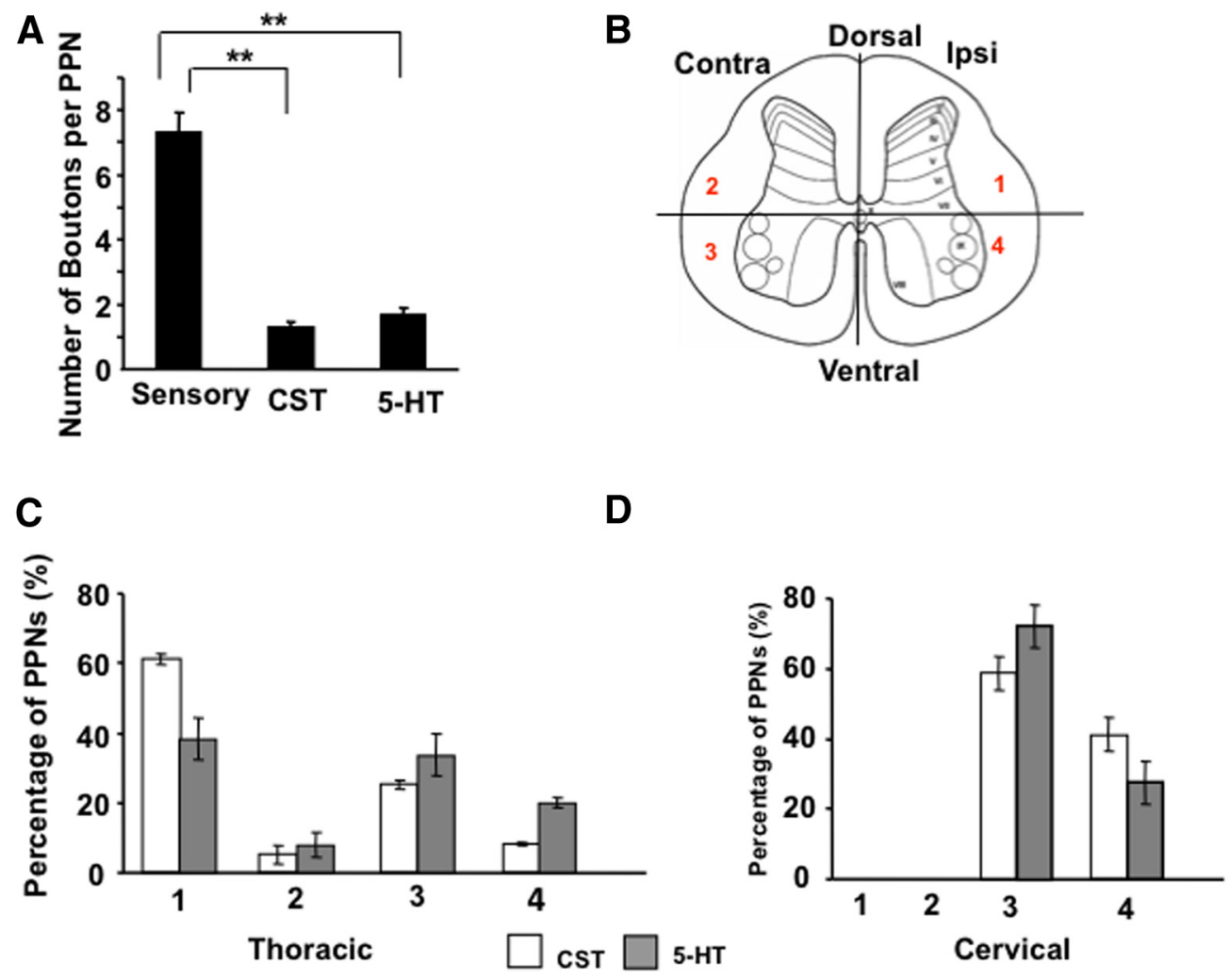

Figure 6. Summary of sensory, CST, and 5-HT synaptic contacts with PPNs. A, Bar graphs represent the average numbers of sensory, CST, or 5-HT synaptic boutons that each PPN receives. $\boldsymbol{B}$, The spinal cord is divided into four regions based on the anatomy of a transverse section, as follows: (1) ipsilateral dorsal area; (2) contralateral dorsal area; (3) contralateral ventral area; and (4) ipsilateral ventral area. C, D, Bar graphs show the percentage of thoracic (C) and cervical (D) PPNs with (ST (white bar) or 5-HT (gray bar) synaptic contacts in the four regions of the spinal cord. ${ }^{* *} p<0.01$, $n=10$, one-way ANOVA followed by Fisher's LSD test.

ever, on the cervical levels, CST and 5-HT axons showed similar innervation patterns (Fig. 6D).

To estimate the contribution of such supraspinal inputs to the overall inputs received by PPNs, we first quantify the average numbers of these supraspinal inputs. The average numbers of CST and 5-HT boutons that PPNs receive are $1.3 \pm 0.2$ and $1.7 \pm$ 0.2 , respectively (Fig. $6 A$ ), which is much lower than that of PV+ sensory boutons $(7.3 \pm 0.6)$. To visualize the total presynaptic inputs to these PPNs, we performed immunohistochemistry with antibodies for presynaptic markers, namely VGluT2 for excitatory synapses (Fig. 7A-C) and VGAT for inhibitory synapses (Fig. 7D-F), respectively. It is known that VGluT2 is the predominant form of glutamate transporter expressed in interneurons inside the spinal cord (Alvarez et al., 2004). VGluT1 boutons in the spinal cord mainly come from either CST or sensory axons. Also, VGAT is responsible for the uptake and storage of both GABA and glycine (Wojcik et al., 2006). Therefore, VGluT2 and VGAT labeling is expected to reveal the numbers of the boutons that each PPN receives from excitatory and inhibitory spinal interneurons. Both cervical and thoracic $\mathrm{PPNs}$ receive an average of $13 \pm 0.8$ excitatory and $13.9 \pm 1.2$ inhibitory synapses (VGluT2, $13 \pm 0.8$; VGAT, $13.9 \pm 1.2$; Fig. $7 G$ ). Although CST and serotonergic axons may also innervate the distal dendrites that are not analyzed here, these results suggested that most PPNs receive either no or few CST and 5-HT inputs in intact mice. The identities of these VGluT2 + and VGAT+ inputs into PPNs remain to be characterized.

\section{PPNs represent a unique type of premotor neuron}

The results above suggested possibly multifunctional roles for these TA-specific PPNs. We next attempted to analyze their cellular and molecular identities. As a first step, we assessed the excitatory and inhibitory compositions of these PPNs by examining the expression of VGluT2 or vesicular inhibitory amino acid transporter (VIAAT), the markers for excitatory or inhibitory neurons, respectively. We found that similar portions of the PPNs belong to excitatory and inhibitory neurons (Fig. $8 A-H, Q$ ), which is consistent with the suggested functional heterogeneities of these PPNs.

Since at least three types of premotor neurons, Renshaw cells (Alvarez and Fyffe, 2007), Ia interneurons (Wang et al., 2008), and cholinergic partition cells (Miles et al., 2007), have been previously identified in the local spinal cord segments, we next assessed whether the PPNs identified here correspond to these neuronal types. By costaining with specific markers for these known premotor neuron types (Fig. $8 I-P$ ), we found that, among all types examined, only one PPN is positively stained with calbindin (Fig. $8 M-P, R$ ), and most PPNs are not positively stained with these markers (Fig. $8 R$ ). Previously, a population of premotor cholinergic partition cells was found around the central canal in the lumbar spinal cord (Stepien et al., 2010). Although some rabies-infected long descending PPNs are also found around the central canal at the thoracic spinal level (Fig. 2G), coimmunostaining with anti-ChAT and GFP antibodies failed to identify any ChAT + PPNs (Fig. $8 I-L$ ). These results suggested that the PPNs are likely to represent a different population of premotor neurons.

\section{A subset of PPNs with Chx10+ origin}

Previous studies identified several classes of spinal interneurons based on their developmental progenitor domain origin (Arber, 2012). Because the majority of labeled PPNs are concentrated in the intermediate spinal cord (Fig. 2), we examined whether a 

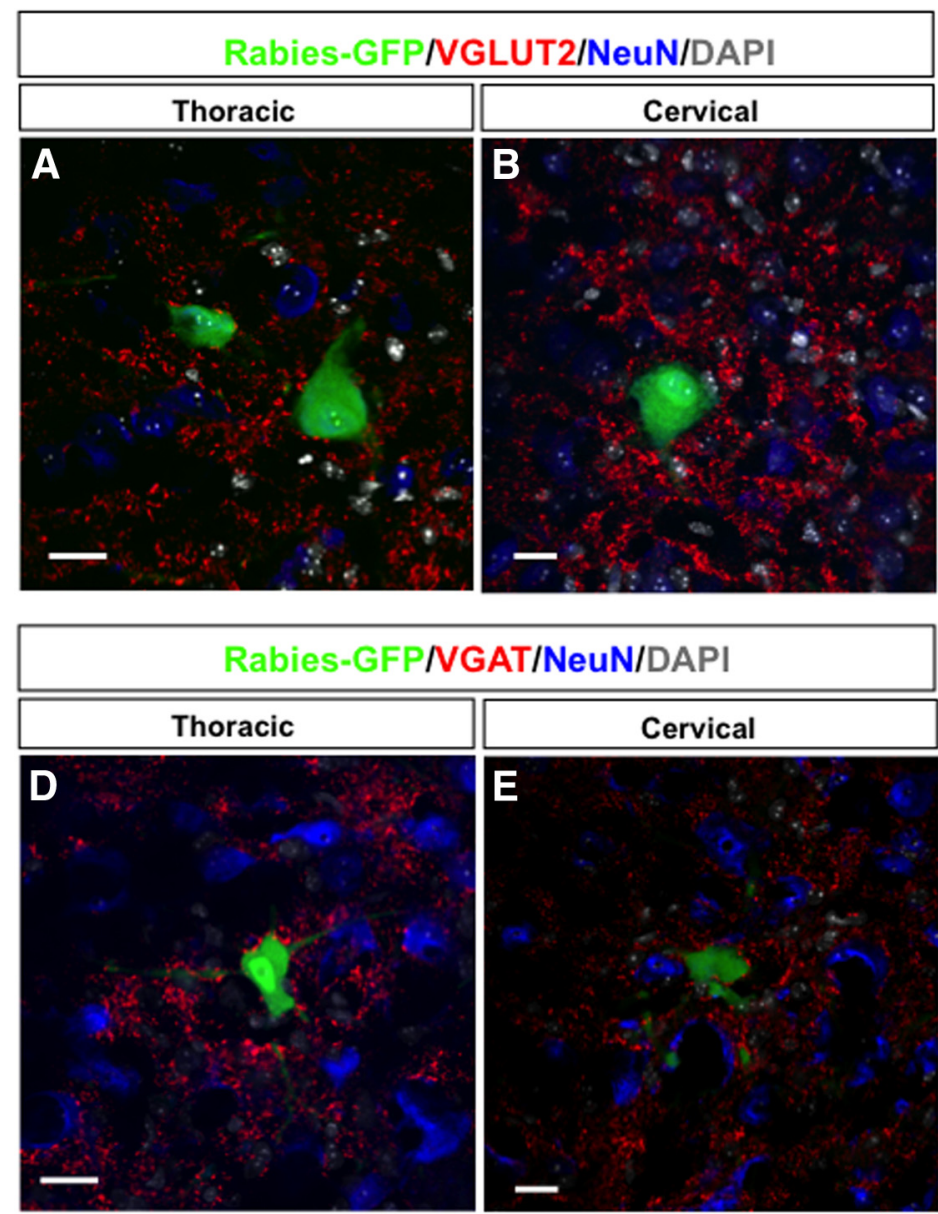

G

\section{- Thoracic a Cervical}
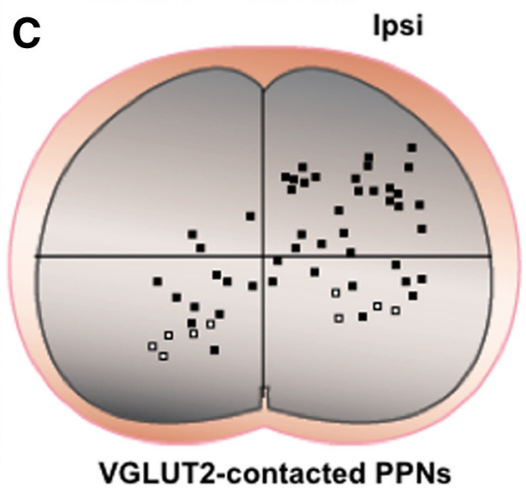

- Thoracic a Cervical

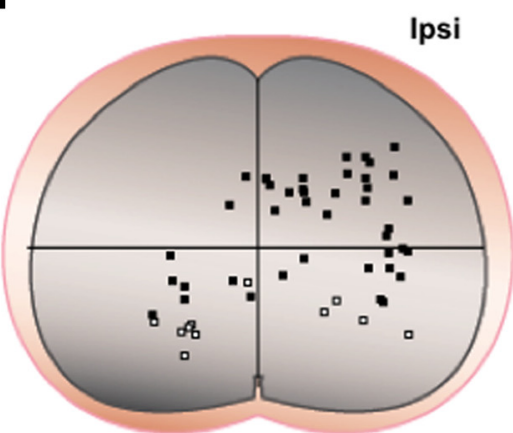

VGAT-contacted PPNs

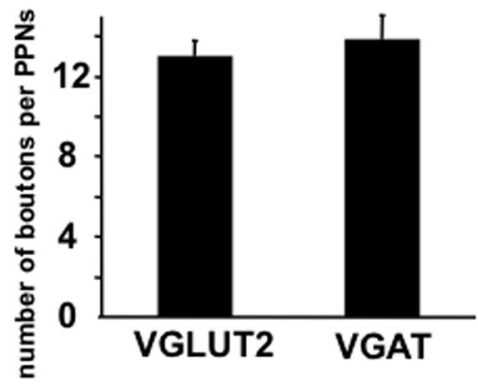

Figure 7. Excitatory and inhibitory synaptic inputs to thoracic and cervical PPNs. $\boldsymbol{A}, \boldsymbol{B}$, Images of thoracic $(\boldsymbol{A})$ and cervical $(\boldsymbol{B})$ spinal transverse sections show rabies-infected PPNs receiving VGluT2-positive excitatory synaptic boutons. NeuN and DAPI costaining are used to label neurons and nuclei. C, The distribution of thoracic (black squares) and cervical (white squares) PPNs with excitatory synaptic boutons in the spinal cord. $\boldsymbol{D}, \boldsymbol{E}$, Images of thoracic $(\boldsymbol{D})$ and cervical $(\boldsymbol{E})$ spinal transverse sections show rabies-infected PPNs receiving VGAT-positive inhibitory synapses. $\boldsymbol{F}$, The distribution of thoracic (black squares) and cervical (white squares) PPNs with inhibitory synaptic boutons in the spinal cord. $\mathbf{G}$, Bar graphs show the average number of excitatory and inhibitory synaptic boutons that each PPN receives. Scale bars: $A, B, D, E, 20 \mu \mathrm{m}$.

relationship between the PPNs and excitatory V2a neurons with similar locations and persistent expression of transcription factor Chx10 was possible (Dougherty and Kiehn, 2010). By coimmunostaining the PPN-labeled thoracic spinal cord sections with antibodies against Chx10 (Fig. 9A,C-E), we found that a subset of rabies-infected PPNs expresses Chx10 in the mediolateral part of the ipsilateral thoracic spinal cord (Fig. 9F,G). This subset of PPNs accounts for $\sim 27 \%$ of the PPNs in the mediolateral spinal cord (Fig. $9 F$ ). These neurons are also restricted in the ipsilateral spinal cord, which is consistent with the notion that Chx10+ V2a neurons are ipsilaterally projecting excitatory interneurons (Al-Mosawie et al., 2007). Thus, our results suggested that at least some PPNs may share similar developmental origins, but these neurons represent a heterogeneous population of spinal interneurons.

\section{Discussion}

By a combination of trans-synaptic rabies viral vector and whole-spinal cord imaging, we established a method to reproduce the labeling of premotor PPNs in the upper spinal cord that directly innervate the motor neurons of individual muscles. While this study has been focused on the hindlimb TA muscle, this procedure may be readily applied to other muscles. Since these propriospinal neurons appear to be highly 

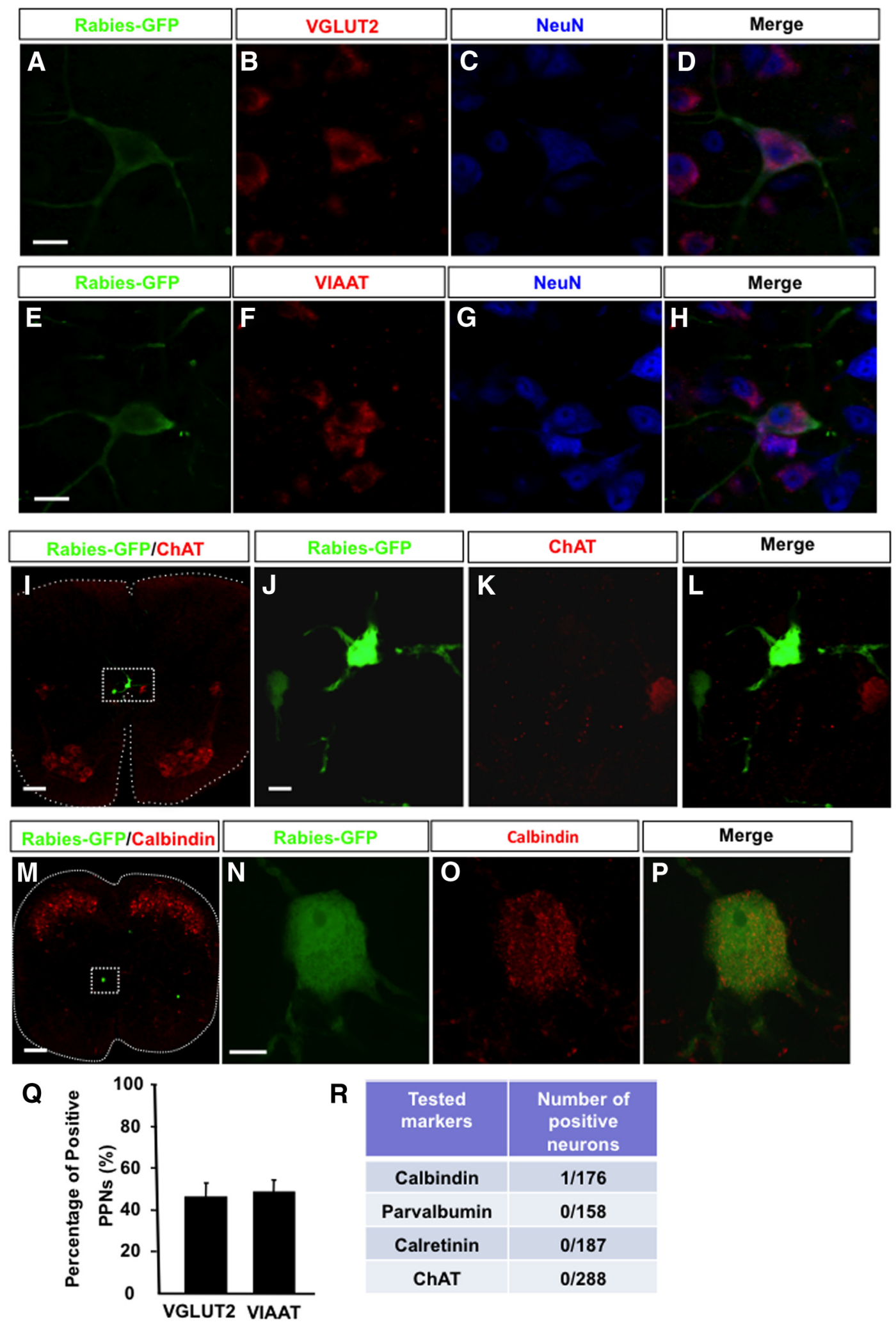

$\mathbf{R}$

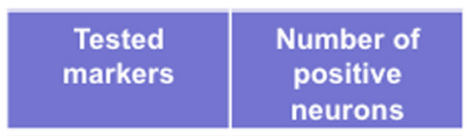

\begin{tabular}{|c|c|}
\hline Calbindin & $1 / 176$ \\
\hline Parvalbumin & $0 / 158$ \\
\hline Calretinin & $0 / 187$ \\
\hline ChAT & $0 / 288$ \\
\hline
\end{tabular}

Figure 8. Molecular characterizations of PPNs. A-D, A PPN with in situ hybridization detected VGluT2 mRNA in the cell body, and immunostained with antibodies against GFP (rabies-GFP) and NeuN. E-H, A PPN with in situ hybridization detected VIAAT mRNA in the cell body, and immunostained with antibodies against GFP (rabies-GFP) and NeuN. I, An image of a thoracic spinal section immunostained with rabies-GFP and ChAT antibodies. The central canal region is highlighted in the boxed area. $J-L$, High-magnification images of the area show two rabies-infected PPNs without ChAT expression. $\boldsymbol{M}$, A calbindin-expressing PPN in the spinal cord section immunostained with rabies-GFP and calbindin antibodies. $\mathbf{N}-\boldsymbol{P}$, High-magnification images show the colocalization of rabies-GFP with calbindin in the identified PPN. $\mathbf{Q}$, Bar graphs show the percentages of excitatory and inhibitory PPNs. $\boldsymbol{R}, A$ table illustrates the results of PPNs tested with individual neuronal markers. Scale bars: $\boldsymbol{A}-\boldsymbol{H}, 20 \mu \mathrm{m} ; \boldsymbol{I}, 100 \mu \mathrm{m} ; \boldsymbol{J}-\boldsymbol{L}, 20 \mu \mathrm{m} ; \boldsymbol{M}, 150 \mu \mathrm{m} ; \boldsymbol{N}-\boldsymbol{P}, 10 \mu \mathrm{m}$. 
A

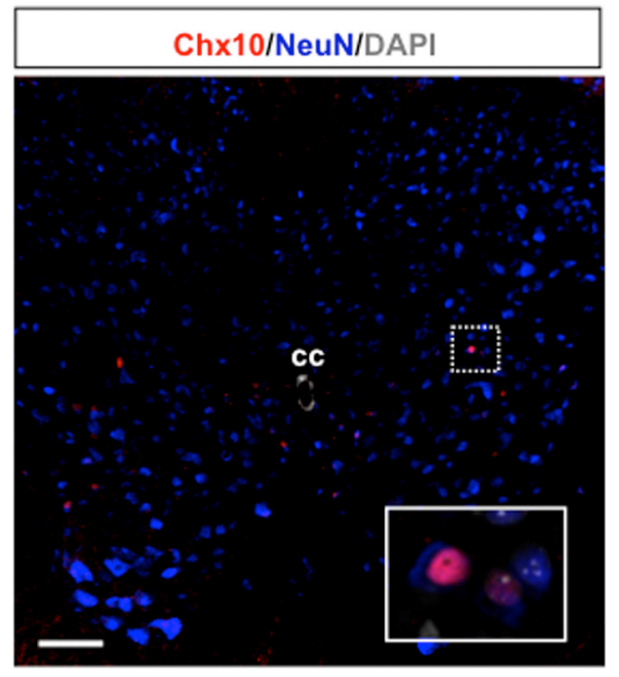

B

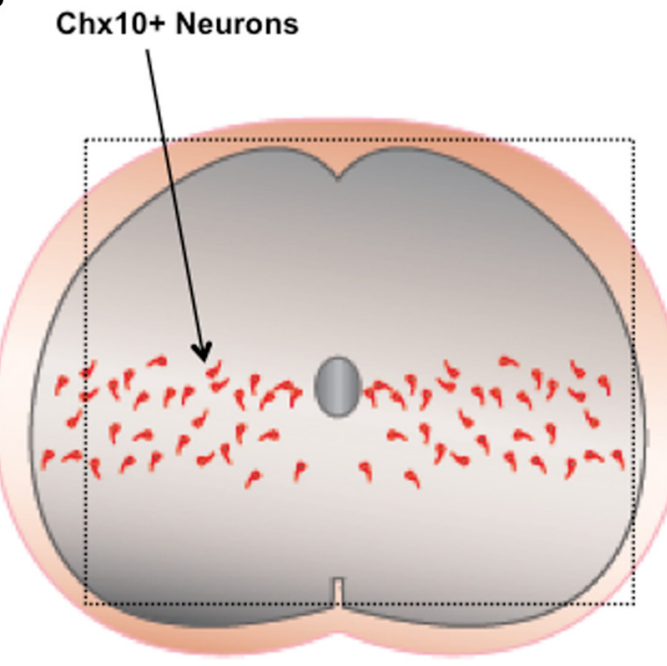

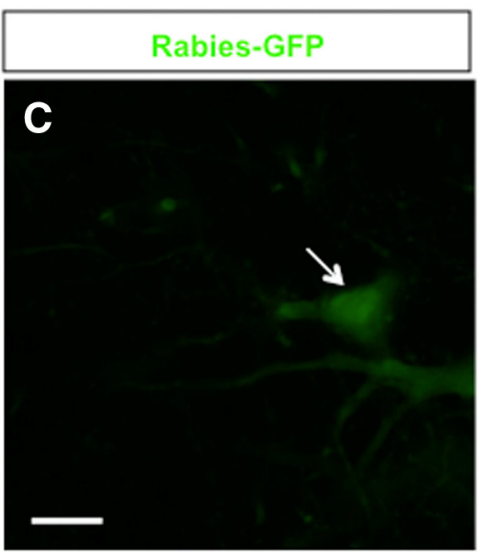
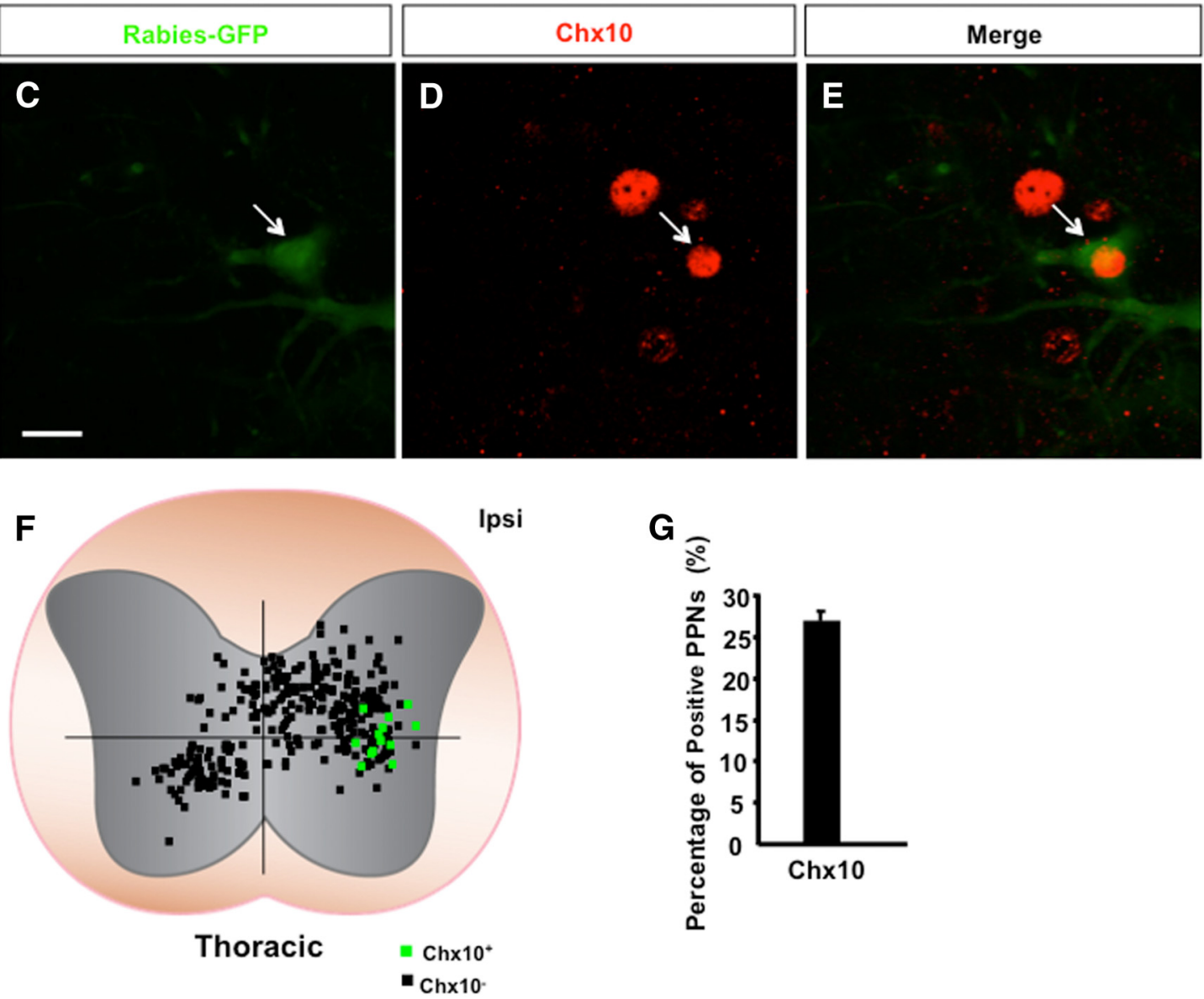

G

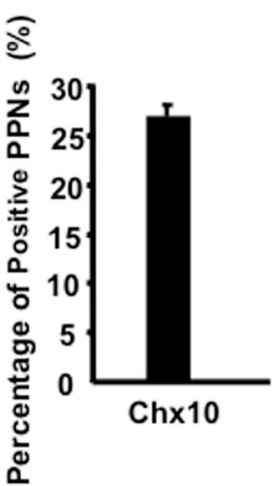

Figure 9. Chx10-expressing neurons in the spinal cord. $A$, An image of a thoracic transverse section from a wild-type mouse immunostained with antibodies against Chx10 and NeuN together with DAPI labeling. The two Chx10-positive neurons highlighted in the boxed area are shown in the inset images. B, A diagram shows the location of Chx10-expressing neurons in the spinal cord. The boxed area shows the location of the region in $\boldsymbol{A}$. (-E, Images of immunostaining of a thoracic spinal section from wild-type mice with antibodies against GFP (rabies-GFP) and Chx10 show a rabies-infected PPN expressing Chx10 (arrow). F, Dot maps represent the distribution patterns of PPNs with (green squares) or without (black squares) Chx10 expression at the thoracic spinal level. G, Bar graphs show the percentage of Chx10-positive thoracic PPNs among the total population of PPNs in their respective area. CC, Central canal; Ipsi, ipsilateral side. Scale bars: $A, 100 \mu \mathrm{m} ; \mathbf{C}-\mathbf{E}, 20 \mu \mathrm{m}$.

heterogeneous and distributed across the entire spinal cord, such a procedure should make systematic characterization of PPNs feasible.

It appears that PPNs could be detected along the entire length of the upper spinal cord. Only small numbers of PPNs are seen in the cervical levels, while the majority of these neurons are en- riched in the lower thoracic levels. Transversely, all cervical PPNs are located in the ventral spinal cord, and most thoracic neurons are located in the intermediate laminae. Thus, cervical PPNs identified in the ventral motor area could directly innervate motor neurons of hindlimb muscles, serving as strong candidates for the regulators of forelimb and hindlimb coordination. 
On the other hand, the large numbers of PPNs in the thoracic spinal cord point to the potential importance of these premotor neurons outside of lumbar enlargement in controlling the activity of lumbar motor control. Interestingly, similar to Ia and $\mathrm{Ib}$ interneurons that mediate proprioceptive feedback to the motor neurons in the same spinal segments (Willis, 2006), a subset of thoracic PPNs receives direct proprioceptive inputs from trunk muscles and projects their axons to the lumbar motor neurons, suggesting the existence of a direct pathway in controlling trunk and hindlimb coordination. However, these PPNs do not share molecular characteristics of Ia and Ib interneurons. In addition, since other types of thoracic PPNs are also located in the intermediate spinal cord, they might also receive indirect sensory inputs, thus participating in the coordination of trunk and hindlimb.

In addition to these putative reflexive functions, the PPNs could be involved in adaptive processes such as injury. We find that about a half of PPNs in both cervical and thoracic levels are innervated by CST or serotonergic axons, but the average bouton numbers are very limited $(<2)$, suggesting the limited influence of these brain-derived inputs to these PPNs on intact animals. Thus, it will be interesting to assess whether these PPNs or other types of propriospinal neurons are innervated by sprouted supraspinal axons during functional recovery. These and other studies may lead to the identification of key neuronal types that mediate spontaneous functional recovery.

\section{References}

Al-Mosawie A, Wilson JM, Brownstone RM (2007) Heterogeneity of V2derived interneurons in the adult mouse spinal cord. Eur J Neurosci 26: 3003-3015. CrossRef Medline

Alvarez FJ, Fyffe RE (2007) The continuing case for the Renshaw cell. J Physiol 584:31-45. CrossRef Medline

Alvarez FJ, Villalba RM, Zerda R, Schneider SP (2004) Vesicular glutamate transporters in the spinal cord, with special reference to sensory primary afferent synapses. J Comp Neurol 472:257-280. CrossRef Medline

Arber S (2012) Motor circuits in action: specification, connectivity, and function. Neuron 74:975-989. CrossRef Medline

Arshavsky YuI, Deliagina TG, Orlovsky GN, Panchin YuV, Pavlova GA, Popova LB (1986) Control of locomotion in marine mollusc Clione limacina. VI. Activity of isolated neurons of pedal ganglia. Exp Brain Res 63:106-112. Medline

Bareyre FM, Kerschensteiner M, Raineteau O, Mettenleiter TC, Weinmann O, Schwab ME (2004) The injured spinal cord spontaneously forms a new intraspinal circuit in adult rats. Nat Neurosci 7:269-277. CrossRef Medline

Bareyre FM, Kerschensteiner M, Misgeld T, Sanes JR (2005) Transgenic labeling of the corticospinal tract for monitoring axonal responses to spinal cord injury. Nat Med 11:1355-1360. CrossRef Medline

Chung K, Coggeshall RE (1983) Propriospinal fibers in the rat. J Comp Neurol 217:47-53. CrossRef Medline

Courtine G, Song B, Roy RR, Zhong H, Herrmann JE, Ao Y, Qi J, Edgerton VR, Sofroniew MV (2008) Recovery of supraspinal control of stepping via indirect propriospinal relay connections after spinal cord injury. Nat Med 14:69-74. CrossRef Medline

Courtine G, Gerasimenko Y, van den Brand R, Yew A, Musienko P, Zhong H, Song B, Ao Y, Ichiyama RM, Lavrov I, Roy RR, Sofroniew MV, Edgerton VR (2009) Transformation of nonfunctional spinal circuits into functional states after the loss of brain input. Nat Neurosci 12:1333-1342. CrossRef Medline

Cowley KC, Zaporozhets E, Schmidt BJ (2010) Propriospinal transmission of the locomotor command signal in the neonatal rat. Ann N Y Acad Sci 1198:42-53. CrossRef Medline

Delwaide PJ, Figiel C, Richelle C (1977) Effects of postural changes of the upper limb on reflex transmission in the lower limb. Cervicolumbar reflex interactions in man. J Neurol Neurosurg Psychiatry 40:616-621. CrossRef Medline

Dougherty KJ, Kiehn O (2010) Firing and cellular properties of V2a in- terneurons in the rodent spinal cord. J Neurosci 30:24-37. CrossRef Medline

Falgairolle M, de Seze M, Juvin L, Morin D, Cazalets JR (2006) Coordinated network functioning in the spinal cord: an evolutionary perspective. J Physiol-Paris 100:304-316. CrossRef Medline

Garcia-Campmany L, Stam FJ, Goulding M (2010) From circuits to behaviour: motor networks in vertebrates. Curr Opin Neurobiol 20:116-125. CrossRef Medline

Grieger JC, Choi VW, Samulski RJ (2006) Production and characterization of adeno-associated viral vectors. Nat Protoc 1:1412-1428. CrossRef Medline

Grillner S (2006) Biological pattern generation: the cellular and computational logic of networks in motion. Neuron 52:751-766. CrossRef Medline

Grillner S, Wallén P (2002) Cellular bases of a vertebrate locomotor system-steering, intersegmental and segmental co-ordination and sensory control. Brain Res Rev 40:92-106. CrossRef Medline

Heise C, Kayalioglu G (2009) Cytoarchitecture of the spinal cord. In: The Spinal Cord (Watson C, Paxinos G, Kayalioglu G, eds), pp 64-80. New York: Academic.

Kostyuk PG, Vasilenko DA (1979) Spinal interneurons. Annu Rev Physiol 41:115-126. CrossRef Medline

Lee JK, Geoffroy CG, Chan AF, Tolentino KE, Crawford MJ, Leal MA, Kang B, Zheng B (2010) Assessing spinal axon regeneration and sprouting in Nogo-, MAG-, and OMgp-deficient mice. Neuron 66:663-670. CrossRef Medline

Maier IC, Baumann K, Thallmair M, Weinmann O, Scholl J, Schwab ME (2008) Constraint-induced movement therapy in the adult rat after unilateral corticospinal tract injury. J Neurosci 28:9386-9403. CrossRef Medline

Miles GB, Hartley R, Todd AJ, Brownstone RM (2007) Spinal cholinergic interneurons regulate the excitability of motoneurons during locomotion. Proc Natl Acad Sci U S A 104:2448-2453. CrossRef Medline

Miller S, Reitsma DJ, van der Meché FG (1973) Functional organization of long ascending propriospinal pathways linking lumbo-sacral and cervical segments in the cat. Brain Res 62:169-188. CrossRef Medline

Moret F, Renaudot C, Bozon M, Castellani V (2007) Semaphorin and neuropilin co-expression in motoneurons sets axon sensitivity to environmental semaphorin sources during motor axon pathfinding. Development 134:4491-4501. CrossRef Medline

Nawabi H, Briançon-Marjollet A, Clark C, Sanyas I, Takamatsu H, Okuno T, Kumanogoh A, Bozon M, Takeshima K, Yoshida Y, Moret F, Abouzid K, Castellani V (2010) A midline switch of receptor processing regulates commissural axon guidance in vertebrates. Genes Dev 24:396-410. CrossRef Medline

Persson S, Boulland JL, Aspling M, Larsson M, Fremeau RT Jr, Edwards RH, Storm-Mathisen J, Chaudhry FA, Broman J (2006) Distribution of vesicular glutamate transporters 1 and 2 in the rat spinal cord, with a note on the spinocervical tract. J Comp Neurol 497:683-701. CrossRef Medline

Rosenzweig ES, Courtine G, Jindrich DL, Brock JH, Ferguson AR, Strand SC, Nout YS, Roy RR, Miller DM, Beattie MS, Havton LA, Bresnahan JC, Edgerton VR, Tuszynski MH (2010) Extensive spontaneous plasticity of corticospinal projections after primate spinal cord injury. Nat Neurosci 13:1505-1510. CrossRef Medline

Sherrington CS, Laslett EE (1902) Note upon descending intrinsic spinal tracts in the mammalian cord. Proc R Soc Lond 71:115-121.

Sherrington CS, Laslett EE (1903) Observations on some spinal reflexes and the interconnection of spinal segments. J Physiol 29:58-96. Medline

Siebert JR, Middleton FA, Stelzner DJ (2010) Long descending cervical propriospinal neurons differ from thoracic propriospinal neurons in response to low thoracic spinal injury. BMC Neurosci 11:148. CrossRef Medline

Skinner RD, Adams RJ, Remmel RS (1980) Responses of long descending propriospinal neurons to natural and electrical types of stimuli in cat. Brain Res 196:387-403. CrossRef Medline

Stelzner DJ (2008) Short-circuit recovery from spinal injury. Nat Med 14: 19-20. CrossRef Medline

Stepien AE, Tripodi M, Arber S (2010) Monosynaptic rabies virus reveals premotor network organization and synaptic specificity of cholinergic partition cells. Neuron 68:456-472. CrossRef Medline

Tripodi M, Stepien AE, Arber S (2011) Motor antagonism exposed by spatial segregation and timing of neurogenesis. Nature 479:61-66. CrossRef Medline 
Tuszynski MH, Steward O (2012) Concepts and methods for the study of axonal regeneration in the CNS. Neuron 74:777-791. CrossRef Medline

Varoqui H, Schäfer MK, Zhu H, Weihe E, Erickson JD (2002) Identification of the differentiation-associated $\mathrm{Na}+/ \mathrm{PI}$ transporter as a novel vesicular glutamate transporter expressed in a distinct set of glutamatergic synapses. J Neurosci 22:142-155. Medline

Wang Z, Li L, Goulding M, Frank E (2008) Early postnatal development of reciprocal Ia inhibition in the murine spinal cord. J Neurophysiol 100: 185-196. CrossRef Medline

Wickersham IR, Finke S, Conzelmann KK, Callaway EM (2007a) Retrograde neuronal tracing with a deletion-mutant rabies virus. Nat Methods 4:47-49. CrossRef Medline
Wickersham IR, Lyon DC, Barnard RJ, Mori T, Finke S, Conzelmann KK, Young JA, Callaway EM (2007b) Monosynaptic restriction of transsynaptic tracing from single, genetically targeted neurons. Neuron 53:639647. CrossRef Medline

Willis WD (2006) John Eccles'studies of spinal cord presynaptic inhibition. Prog Neurobiol 78:189-214. CrossRef Medline

Wojcik SM, Katsurabayashi S, Guillemin I, Friauf E, Rosenmund C, Brose N, Rhee JS (2006) A shared vesicular carrier allows synaptic corelease of GABA and glycine. Neuron 50:575-587. CrossRef Medline

Zampieri N, Jessell TM, Murray AJ (2014) Mapping sensory circuits by anterograde transsynaptic transfer of recombinant rabies virus. Neuron 81: 766-778. CrossRef Medline 